\title{
Radio-protective role of antioxidant agents
}

\author{
Alireza Shirazi, ${ }^{1}$ Ehsan Mihandoost, ${ }^{2}$ Seied Rabie Mahdavi, ${ }^{1}$ Mehran Mohseni ${ }^{3}$ \\ 'Department of Medical Physics and Biomedical Engineering, Faculty of Medicine, Tehran \\ University of Medical Sciences, Tehran; ${ }^{2}$ Department of Medical Radiation Engineering, Science \\ and Research Branch, Islamic Azad University, Tehran; ${ }^{3}$ Department of Radiology and Medical \\ Physics, Faculty of Paramedicine, Kashan University of Medical Sciences, Kashan, Iran
}

\begin{abstract}
Ionizing radiation interacts with biological systems to produce reactive oxygen species and reactive nitrogen species which attack various cellular components. Radio-protectors act as prophylactic agents to shield healthy cells and tissues from the harmful effects of radiation. Past research on synthetic radio-protectors has brought little success, primarily due to the various toxicity-related problems. Results of experimental research show that antioxidant nutrients, such as vitamin $\mathrm{E}$ and herbal products and melatonin, are protective against the damaging effects of radiation, with less toxicity and side effects. Therefore, we propose that in the future, antioxidant radio-protective agents may improve the therapeutic index in radiation oncology treatments.
\end{abstract}

\section{Introduction}

The ability of potent protective agents to provide protection against the damaging effects of ionizing radiation was first reported in 1949.1 Research efforts with synthetic radio-protectors in the past brought lit-

Correspondence: Ehsan Mihandoost, Department of Medical Radiation Engineering, Science and Research Branch, Islamic Azad University, Tehran, Iran. Tel. +982144444891. E-mail: mihandoost.e@gmail.com

Key words: radio-protectors, antioxidants, herbal radio-protectors, vitamin E, melatonin.

Contributions: AS, all sections of this work; EM, all sections of this work specially radiobiological considerations and melatonin; SRM, sections on radiobiological considerations and antioxidant nutrients; MM, section on antioxidant nutrients.

Conflict of interests: the authors delcare no potential conflict of interests.

Received for publication: 22 March 2012.

Revision received: 22 March 2012.

Accepted for publication: 5 July 2012.

This work is licensed under a Creative Commons Attribution NonCommercial 3.0 License (CC BY-NC 3.0).

CCopyright A. Shirazi et al., 2012

Licensee PAGEPress, Italy

Oncology Reviews 2012; 6:e16

doi:10.4081/oncol.2012.e16 tle success primarily due to the various toxicity-related problems. ${ }^{2}$ The most efficient radio-protective agents that were originally tested against lethal doses of $\mathrm{X}$ rays and gamma radiation in mice is WR2721 , also known as amifostine. ${ }^{2}$ Although amifostine was reported to be an effective radio-protector in clinical radiation oncology, it was later found to cause some undesirable side effects, such as hypotension, vomiting, nausea, sneezing, hot flashes, mild somnolence and hypocalcemia. $^{3}$

Results obtained from animal experiments show that antioxidant nutrients, such as vitamin $\mathrm{A}, \mathrm{C}$ and $\mathrm{E},{ }^{4}$ and a large number of herbal productions ${ }^{5}$ are protective against lethality and other radiation effects. ${ }^{4}$ Furthermore, a large number of papers have been published confirming the ability of melatonin, a pineal gland hormone, to protect against radiation-induced damage. . $^{3,6,7}$

This review briefly covers the effects of irradiation on biological systems and presents various features that make antioxidants a potent radio-protector in radiation oncology trials.

\section{Radiobiological considerations}

Exposure of biological systems to ionizing radiation leads to formation of reactive oxygen species (ROS) and reactive nitrogen species. ${ }^{8}$ These reactive species damage the various bio-macromolecules, like the DNA, lipids and proteins present in the cell. ${ }^{9}$ Furthermore, exposure to high doses of ionizing radiation results in damage to the hematopoietic, gastrointestinal or central nervous systems, depending on radiation dose (Table 1$)^{6,10}$ Since the hematopoietic system has a high level of cell turnover; it has among the most radiosensitive tissues in the body. ${ }^{11,12}$ Gastrointestinal and central nervous syndromes are induced by a higher irradiation dose compared to hematopoietic syndrome. ${ }^{13}$ An understanding of the biological effects of irradiation is necessary in order to understand the important role of radio-protective agents.

\section{Antioxidant nutrients}

Antioxidant agents, such as vitamin A, C and E, offer protective properties against radiation because deleterious effects of radiation mimics the oxidative damage associated with active oxygen toxicity. ${ }^{14}$ Selenium ( $\left(\mathrm{as}_{2} \mathrm{SeO}_{3}\right)$ and vitamin $\mathrm{E}$ have been reported to act alone and in an additive form as radio-protective and chemo-preventive agents. $^{15}$

Ebselen, a seleno-organic compound, has been shown to protect cells against the damaging effects of radiation caused by ROS. ${ }^{16}$ When 
cells were exposed to 2 Gy and 20 Gy of gamma irradiation, there was a significant difference between the untreated cells and the cells pretreated with ebselen with respect to apoptotic features and mitochondrial function. Ebselen administration for 14 days at a daily dosage of $10 \mathrm{mg} / \mathrm{kg}$ provided significant protection against killing and oxidative damage to mice exposed to whole-body gamma irradiation. These data show that ebselen may have great potential as a new class of in vivo, non-sulfur containing radio-protectors. ${ }^{16}$

Many animal studies have recently been published on the radio-protective effects of propolis. ${ }^{17}$ Propolis is a resinous substance collected by honey bees. Ethanolic extract of propolis is effective in reducing and delaying radiation-induced mucositis in an animal model. ${ }^{17}$

Results from animal experiments indicate that antioxidant nutrients are protective against lethality and other radiation effects but to a lesser degree than most synthetic radio-protectors, such as amifostine. However, some antioxidant nutrients have the advantage of low toxicity even though they are generally protective when administered at pharmacological doses. ${ }^{4}$

\section{Vitamin E}

Vitamin E (alpha tocopherol) and related analogs are nutraceuticals that can scavenge singlet oxygen and superoxide anion radicals. ${ }^{18}$ Vitamin E has been shown to maintain jejunal, ileal, and colonic fluid absorption in irradiated rats, ${ }^{18}$ even when treatment with vitamin $\mathrm{E}$ after 1 Gy radiation exhibited protective effects against radiation induced chromosomal aberrations and micronuclei in mouse bone marrow. ${ }^{19} \mathrm{~A}$ water-soluble vitamin E derivative, tocopherol monoglucoside (TMG), was reported to be very effective in protecting DNA both in vitro and also in mice after oral or intraperitoneal administration against gamma irradiation. ${ }^{20}$

TMG [(2-a-D-glucopyranosyl) methyl-2, 5, 7, 8-tetramethylchroman6-ol], was efficient when administered immediately after radiation exposure at a dose of $600 \mathrm{mg} / \mathrm{kg}$. The treatment decreased radiationinduced abnormal metaphases in mouse bone marrow chromosomes and reduced the frequency of micronucleated erythrocytes at $24 \mathrm{~h}$ after exposure to radiation. ${ }^{21}$ TMG administered before exposure to radiation also protected against radiation-induced teratogenesis in mice. ${ }^{22}$

Noaman et al. ${ }^{23}$ showed that vitamin E and selenium (Se) protect antioxidant enzymes in irradiated animals. In this study, rats were injected intraperitoneally with $200 \mathrm{mg} / \mathrm{kg}$ body weight (body wt.) of vitamin $\mathrm{E}$ and sodium selenite ( $0.1 \mathrm{mgSe} / \mathrm{kg}$ body wt.) for ten days before exposure to gamma radiation at 6.5 Gy. Radiation-induced depressions in blood glutathione (GSH), glutathione peroxidase (GSH$\mathrm{Px}$ ), and superoxide dismutase (SOD), and increases in plasma lipid peroxide products were normalized in the irradiated rats that were treated with combined vitamin $\mathrm{E}$ and $\mathrm{Se} .^{23}$

The extent of changes in antioxidant enzymes levels after irradiation may differ according to animal tissue, but vitamin $\mathrm{E}$ and Se administration tends to normalize the enzyme levels in irradiated tissue. ${ }^{24}$ Also, most studies support other evidence for the synergistic effects of vitamin $\mathrm{E}$ and $\mathrm{Se}$ in protecting against the oxidative damage caused by radiation. ${ }^{25}$ However, further studies are needed to confirm these radio-protective effects.

\section{Herbal radio-protectors}

The majority of synthetic radio-protectors have limited clinical application owing to their side effects and inherent toxicity. ${ }^{13,26,27}$ Therefore, natural herbal radio-protectors, such as Ginkgo biloba, Chaga mushroom, green tea (polyphenols), dithiolthiones, Panax ginseng, Shigoka extract, and Spirulina platensis, have become an important alternative. ${ }^{27}$

The proposed radio-protective efficacy of plant products is due to their containing a large number of active constituents, such as antioxidants, immunostimulants and compounds with antimicrobial activity. ${ }^{27}$ Citrus extract, at a dose of $250 \mathrm{mg} / \mathrm{kg}$, was reported to mitigate the genotoxicity induced by gamma radiation, when administrated $1 \mathrm{~h}$ before gamma radiation. Citrus extract protected mice bone marrow 2.2-fold, compared to the non-drug-treated irradiated control. ${ }^{26}$

The radio-protective effect of hawthorn (Crataegus microphylla) fruit extract was investigated in cultured blood lymphocytes of human volunteers exposed in vitro to $150 \mathrm{cGy}$ of gamma radiation. Results suggest that it may be possible to use hawthorn extracts in personnel exposed to radiation in order to protect lymphocytes from the damaging effects of radiation. ${ }^{28}$

The doses of herbal preparations that were effective in protecting against irradiation was significantly lower than the toxic dose of synthetic compounds, and this is one of the major advantages of these agents compared to synthetic compounds. ${ }^{13}$ The use of plants as radioprotectors has some disadvantages, such as low to mild efficacy and a short protective time-window (in most cases 30 min to $2 \mathrm{~h}$ before irradiation). ${ }^{13}$

\section{Panax ginseng}

Since the 1980s, the radio-protective effects of both Panax ginseng $(P$. ginseng) and its partially purified constituents have been demonstrated in experimental tests. ${ }^{29-38}$ The strong free radical scavenging effects of $P$. ginseng have been extensively reported. ${ }^{39-46}$ Studies have

Table 1. Radiation sickness.

System effected/syndrome Symptoms Dose

Nervous system

CNS or cerebrovascular syndrome

Shock, severe nausea, disorientation, seizures, coma

$10,000,000$ mrem

G.I. system

Gastrointestinal syndrome

Nausea, vomiting, diarrhea, dehydration

$1,000,000$ mrem

Blood cells /bone marrow

Hematopoietic syndrome

Chills, fatigue, hemorrhage, ulceration, infections, anemia

$300,000-800,000$ mrem

$\begin{array}{lll}\text { Skin } & \text { Burning/infection, sloughing of skin, hair loss } & 1,000,000 \mathrm{mrem} \\ \text { Erethema } & \text { Sterility } & 60,000-80,000 \mathrm{mrem} /\end{array}$

250,000-600,000 mrem

CNS, central nervous system; G.I., gastrointestinal. 


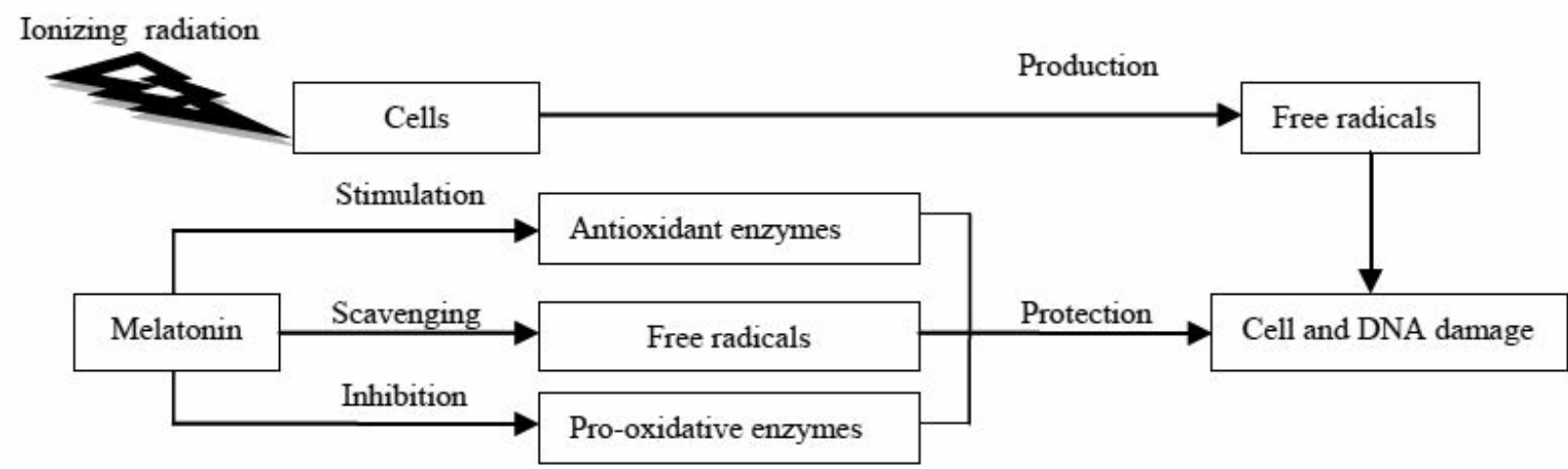

Figure 1. Radio-protective mechanism of melatonin.

shown that ginseng root extracts present both lipid-soluble and watersoluble antioxidant activity, and that this antioxidant action occurs both directly through free radical scavenging and indirectly through upregulation of antioxidant enzymes. ${ }^{39,40,42,44,46}$ leading to the prevention of DNA degradation. ${ }^{39,40,45,46}$ Kumar et al. ${ }^{47}$ reported that administration of $P$. ginseng root extract before radiation significantly decreased lipid peroxidation levels and reduced the radiation damage in mice testes. Furthermore, studies have demonstrated the immunomodulating effects of $P$. ginseng in different irradiated animal models. Hsu et al.$^{48}$ have found that, in mice, the administration of $P$. ginseng before whole body radiation significantly protected both bone marrow stem cells and peripheral hematocytes, thereby reducing the magnitude of radiation-induced regression in the immunohematopoietic system.

\section{Melatonin: another remarkable radio-protector}

Melatonin (N-acetyl-5-methyloxytryptamine), a pineal gland hormone involved in regulating the neuroendocrine axis, is a highly efficient free-radical scavenger and antioxidant. ${ }^{7,49-51}$ Melatonin has been reported to be a direct free-radical scavenger and an indirect antioxidant via its stimulative effects on antioxidant enzymes, ${ }^{6,52-54}$ such as SOD, GSH-Px, glutathione reductase, and catalase ${ }^{55-59}$ (Figure 1). Melatonin also increases intracellular GSH levels by stimulating the synthesis of the rate-limiting enzyme, $\gamma$-glutamylcysteine synthase, which inhibits the pero-oxidative enzymes nitric oxide synthase and lipoxygenase ${ }^{55,60,61}$ (Figure 1).

A large number of studies have indicated the protective effects of melatonin against oxidative stress induced by irradiation. ${ }^{55}$ Radiation myelopathy (RM) is known to be one of the most important complications of radiation in clinical radiotherapy and studies have exhibited dose and time dependent radiation effects. Destructive changes in the white matter infrastructure constitute the main histopathological event. ${ }^{62,63}$ We have previously assessed the radio-protective effects of melatonin on biochemical, histopathological, and clinical manifestations of RM in rat cervical spinal cord. Administration of melatonin significantly decreased malondialdehyde (MDA) and increased GSH levels when compared with the control group. ${ }^{60,64}$ Furthermore, our new data obtained from another study showed that radiation exposure decreased levels of GSH and increased levels of MDA in rat lenses, but these values were within normal limits when melatonin was administered. ${ }^{65}$ It was shown that melatonin decreased the formation of 8-hydroxy-2 deoxyguanosine, a damaged DNA product caused by free radicals, 60 to 70 times more effectively than some classic antioxidants (ascorbate and $\alpha$-tocopherol). ${ }^{66}$ Thus, melatonin acts as a direct scavenger of free radicals and an indirect stimulator of the activity of the antioxidative defense systems ${ }^{66-69}$ (Figure 1).

In another study, Shirazi et al. ${ }^{70}$ examined the role of melatonin to reduce radiation-induced apoptosis in rat cervical spinal cord. Results from this study suggest that melatonin has protective effects against radiation-induced apoptosis. The principal finding in this work is that melatonin increased $B c l-2$ gene expression with a significant decrease in $B a x$ gene expression in irradiated spinal cord. The role of melatonin as an anti-apoptotic agent in healthy cells is a new field of investigation, and information is still limited. ${ }^{70}$

\section{Conclusions}

Research into radio-protective agents must continue in order to find novel radio-protectors that can protect against radiation-induced damage in cells and tissues. Although radio-protectors may be able to minimize the life-threatening effects of irradiation, few radio-protective agents are in clinical use due to undesirable side effects, such as hypotension, vomiting, nausea, sneezing, hot flashes, etc. Therefore, the development of antioxidant radio-protectors with less toxicity are essential areas of radiobiological research as methods of improving the therapeutic index in treatment of patients who have received radiotherapy or other kinds of radiation application.

\section{References}

1. Dale W, Gray L, Meredith W. The inactivation of an enzyme (Carboxypeptidase) by X-and alpha radiation. Philos Trans R Soc London (A) 1949;242:33.

2. Bump E, Malaker K. Radioprotectors: chemical, biological, and clinical perspectives. Boca Raton, FL: CRC Press; 1997.

3. Vijayalaxmi M, Reiter R, Herman T, Kumar K. Melatonin and protection from whole-body irradiation: survival studies in mice. Mutat Res 1999;425:21-7.

4. Weiss J, Landauer M. Protection against ionizing radiation by antioxidant nutrients and phytochemicals. Toxicology 2003;189:120.

5. Nair C, Parida D, Nomura T. Radioprotectors in radiotherapy. J Radiat Res 2001;42:21-37.

6. Shirazi A, Ghobadi G, Ghazi-Khansari M. A radiobiological review on melatonin: a novel radioprotector. J Radiat Res 2007;48:263-72. 
7. Vijayalaxmi R, Herman T, Meltz M. Melatonin and radioprotection from genetic damage: in vivo/in vitro studies with human volunteers. Mutat Res 1996;371:221-8.

8. Arora R. Herbal radiomodulators: applications in medicine, homeland defence and space. Wallingford: CABI Publishing; 2008.

9. Prasad K. Handbook of radiobiology. Boca Raton, FL: CRC Press; 1999.

10. Prasad K. Handbook of radiobiology. Boca Raton, FL: CRC Press; 1995.

11. Hsu H, Lin C. A preliminary study on the radioprotection of mouse hematopoiesis by Dang-Gui-Shao-Yao-San. J Ethnopharmacol 1996;55:43-8.

12. Miyanomae T, Frindel E. Radioprotection of hemopoiesis conferred by Acanthopanax senticosus Harms (Shigoka) administered before or after irradiation. Exper Hematol 1988;16:801.

13. Hosseinimehr S. Trends in the development of radioprotective agents. Drug Discov Today 2007;12:794-805.

14. Konopacka M. Vitamins as radioprotectors of normal cells. Postepy Hig Med Dosw 1996;50:145.

15. Borek C, Ong A, Mason H, et al. Selenium and vitamin E inhibit radiogenic and chemically induced transformation in vitro via different mechanisms. Proc Natl Acad Sci U S A 1986;83:1490.

16. Tak J, Park J. The use of ebselen for radioprotection in cultured cells and mice. Free Radic Biol Med 2009;46:1177-85.

17. Ghassemi L, Zabihi E, Mahdavi R, et al. The effect of ethanolic extract of propolis on radiation-induced mucositis in rats. Saudi Med J 2010;31:622.

18. Empey L, Papp J, Jewell L, Fedorak R. Mucosal protective effects of vitamin $\mathrm{E}$ and misoprostol during acute radiation-induced enteritis in rats. Digest Dis Sci 1992;37:205-14.

19. Sarma L, Kesavan P. Protective effects of vitamins C and E against -ray-induced chromosomal damage in mouse. Int $\mathrm{J}$ Radiat Biol 1993;63:759-64.

20. Nair C, Wani K, Rajagopalan R, et al. Mechanism of radioprotection by TMG, a water soluble vitamin E. Proc Ann Conf Japan Radiat Res Soc, September 1-3, 1999, Hiroshima, Japan.

21. Satyamitra M, Devi P, Murase H, Kagiya V. In vivo radioprotection by alpha-TMG: preliminary studies. Mutat Res 2001;479:53-61.

22. Gu Y, Hasegawa T, Kim H, Suzuki I, Mori T, Yamamoto Y. Study of the radioprotective effects of TMG on teratogenic malformations in irradiated mice. Nihon Igaku Hoshasen Gakkai Zasshi 2000;60:845-55.

23. Noaman E, Zahran A, Kamal A, Omran M. Vitamin E and selenium administration as a modulator of antioxidant defense system. Biol Trace Elem Res 2002;86:55-64.

24. Mutlu-Türkolu U, Erbil Y, Oztezcan S, et al. The effect of selenium and/or vitamin $\mathrm{E}$ treatments on radiation-induced intestinal injury in rats. Life Sci 2000;66:1905-13.

25. Chow CK. Interrelationship of cellular antioxidant defense systems. In: C.K. Chow (ed.). Cellular antioxidant defense mechanisms, vol. 2. Boca Raton, FL: CRC Press; 1988. pp 217-237.

26. Hosseinimehr S, Tavakoli H, Pourheidari G, et al. Radioprotective effects of citrus extract against -irradiation in mouse bone marrow cells. J Radiat Res 2003;44:237-41.

27. Lee T, Johnke R, Allison R, et al. Radioprotective potential of ginseng. Mutagenesis 2005;20:237-43.

28. Hosseinimehr S, Mahmoudzadeh A, Azadbakht M, Akhlaghpoor S. Radioprotective effects of hawthorn against genotoxicity induced by gamma irradiation in human blood lymphocytes. Radiat Environ Biophys 2009;48:95-8.

29. Song J, Han S, Bae K, et al. Radioprotective effects of ginsan, an immunomodulator. Radiat Res 2003;159:768-74.

30. Ben-Hur E, Fulder S. Effect of Panax ginseng saponins and Eleutherococcus senticosus on survival of cultured mammalian cells after ionizing radiation. Am J Chin Med 1981;9:48-56.

31. Kim S, Cho C, Yoo S, et al. In vivo radioprotective activity of Panax ginseng and diethyldithiocarbamate. In Vivo 1993;7:467-70.

32. Kim S, Jo S, Kim S. Modification of radiation response in mice by ginsenosides, active components of Panax ginseng. In Vivo 2003;17:77-81.

33. Zhang J, Sigdestad C, Gemmell M, Grdina D. Modification of radiation response in mice by fractionated extracts of Panax ginseng. Radiat Res 1987;112:156-63.

34. Hsu H, Yang J, Lian S, et al. Recovery of the hematopoietic system by Si-Jun-Zi-Tang in whole body irradiated mice. J Ethnopharmacol 1996;54:69-75.

35. Kim S, Lee $\mathrm{S}, \mathrm{Oh} \mathrm{H}$, et al. The radioprotective effects of bu-zhongyi-qi-tang: a prescription of traditional Chinese medicine. Am J Chin Med 2002;30:127-38.

36. Kim S, Son C, Nah S, et al. Modification of radiation response in mice by Panax ginseng and diethyldithiocarbamate. In Vivo 2001;15:407-11.

37. Kim S, Kim S, Lee H, et al. Apoptosis in growing hair follicles following gamma-irradiation and application for the evaluation of radioprotective agents. In Vivo 2003;17:211-4.

38. Kim T, Lee $\mathrm{Y}$, Cho $\mathrm{C}$, et al. Protective effect of ginseng on radiationinduced DNA double strand breaks and repair in murine lymphocytes. Cancer Biother Radiopharm 1996;11:267-72.

39. Kitts D, Wijewickreme A, Hu C. Antioxidant properties of a North American ginseng extract. Mol Cellul Biochem 2000;203:1-10.

40. Kitts D, Hu C. Efficacy and safety of ginseng. Public Health Nutr 2000;3:473-85.

41. Gillis C. Panax ginseng pharmacology: a nitric oxide link? Biochem Pharmacol 1997;54:1-8.

42. Kim Y, Guo Q, Packer L. Free radical scavenging activity of red ginseng aqueous extracts. Toxicology 2002;172:149-56.

43. Valli G, Giardina E. Benefits, adverse effects and drug interactionsof herbal therapies with cardiovascular effects. J Am Coll Cardiol 2002;39:1083-95

44. Attele A, Zhou Y, Xie J, et al. Antidiabetic effects of Panax ginseng berry extract and the identification of an effective component. Diabetes 2002;51:1851.

45. Keum Y, Park K, Lee J, et al. Antioxidant and anti-tumor promoting activities of the methanol extract of heat-processed ginseng. Cancer Lett 2000;150:41-8.

46. Zhang D, Yasuda T, Yu Y, et al. Ginseng extract scavenges hydroxyl radical and protects unsaturated fatty acids from decomposition caused by iron-mediated lipid peroxidation. Free Radic Biol Med 1996;20:145-50.

47. Kumar M, Sharma M, Saxena P, Kumar A. Radioprotective effect of Panax ginseng on the phosphatases and lipid peroxidation level in testes of Swiss albino mice. Biol Pharm Bull 2003;26:308-12.

48. Phillips S, Ruggier R, Hutchinson S. Zingiber officinale (ginger),an antiemetic for day case surgery. Anaesthesia 1993;48:715-7.

49. Reiter R. Functional pleiotropy of the neurohormone melatonin: antioxidant protection and neuroendocrine regulation. Front Neuroendocrinol 1995;16:383-415.

50. Pierrefiche G, Laborit H. Oxygen free radicals, melatonin, and aging. Exp Gerontol 1995;30:213-27.

51. Pieri C, Marra M, Moroni F, et al. Melatonin: a peroxyl radical scavenger more effective than vitamin E. Life Sci 1994;55:PL271-6.

52. Tan D, Chen L, Poeggeler B, et al. Melatonin: a potent, endogenous hydroxyl radical scavenger. Endocr J 1993;1:57-60.

53. Mallo C, Zaidan R, Galy G, et al. Pharmacokinetics of melatonin in man after intravenous infusion and bolus injection. Eur $\mathrm{J}$ Clin Pharmacol 1990;38:297-301.

54. Shirazi A, Mihandoost E, Mohseni M, et al. Radio-protective effects 
Prostaglandins Leukot Essent Fatty Acids 2005;72:373-8.

of melatonin against irradiation-induced oxidative damage in rat peripheral blood. Phys Med 2011. [Epub ahead of print].

55. Karbownik M, Reiter R. Antioxidative effects of melatonin in protection against cellular damage caused by ionizing radiation. Proc Soc Exp Biol Med 2000;225:9-22.

56. Reiter RJ, Guerrero JM, Garcia JJ, Acuña-Castroviejo D. Reactive oxygen intermediates, molecular damage, and aging: relation to melatonin. Ann N Y Acad Sci 1998;854:410-24.

57. Reiter RJ. Antioxidant actions of melatonin. Adv Pharmacol 1996;38:103-17.

58. Reiter RJ. Oxidative processes and antioxidative defense mechanisms in the aging brain. FASEB J 1995;9:526-33.

59. Reiter RJ. Oxidative damage in the central nervous system: protection by melatonin. Progr Neurobiol 1998;56:359-84.

60. Shirazi A, Haddadi G, Ghazi-khansari M, et al. Evaluation of melatonin for prevention of radiation myelopathy in irradiated cervical spinal cord. Cell J (Yakhteh) 2009;11:43-8.

61. Shirazi A, Fardid R, Mihandoost E. Protective effect of low dose melatonin on radiation-induced damage to rat liver. J Biomed Phys Eng 2012;2.

62. Shirazi A, Mahdavi S, Trott K. Radiation myelopathy: a radiobiological review. Rep Pract Oncol Radiother 2004;9:119-27.

63. Shirazi A, Rabie Mahdavi S, Minaee B, et al. Short-term changes in prostacyclin secretory profile of irradiated rat cervical spinal cord.
64. Aghazadeh S, Azarnia M, Shirazi A, et al. Melatonin as a protective agent in spinal cord damage after gamma irradiation. Rep Pract Oncol Radiother 2007;12:95-9.

65. Shirazi A, Haddadi G, Asadi-Amoli F, et al. Radioprotective effect of melatonin in reducing oxidative stress in rat lenses. Cell $\mathrm{J}$ (Yakhteh) 2011;13:79-82.

66. Qi W, Reiter R, Tan D, et al. Increased level of oxidatively damaged DNA induced by chromium (III) and $\mathrm{H}_{2} \mathrm{O}_{2}$ : protection by melatonin and related molecules. J Pineal Res 2001;29:54-61.

67. Reiter R, Tan D, Manchester L, Qi W. Biochemical reactivity of melatonin with reactive oxygen and nitrogen species. Cell Biochem Biophys 2001;34:237-56.

68. Tan D, Reiter R, Manchester L, et al. Chemical and physical properties and potential mechanisms: melatonin as a broad spectrum antioxidant and free radical scavenger. Curr Top Med Chem 2002; 2:181-97.

69. Cagnoli C, Atabay C, Kharlamova E, Manev H. Melatonin protects neurons from singlet oxygen-induced apoptosis. J Pineal Res 1995; 18:222-6.

70. Shirazi A, Haddadi G, Minaee B, et al. Evaluation of melatonin for modulation of apoptosis-related genes in irradiated cervical spinal cord. Int J Low Radiat 2010;7:436-45. 